\section{Correspondence on 'Call for action in ANCA- associated vasculitis and lupus nephritis: promises and challenges of SGLT-2 inhibitors' by Säemann and Kronbichler}

Säemann and Kronbichler provided in their published article an excellent perspective on the potential place of sodiumglucose cotransporter-2 (SGLT-2) inhibitors in the treatment armamentarium against antineutrophil cytoplasmic antibodies (ANCA)-associated vasculitis and lupus nephritis (LN). ${ }^{1}$ Besides the described mechanisms of action, it seems that their effect against tubular damage and atrophy could also be crucial for the mediated nephroprotection in LN. It has been previously shown that interstitial fibrosis and tubular atrophy are strongly associated with the risk for progression to end-stage renal disease in subjects with LN, also increasing the overall mortality burden. ${ }^{2}$ In a previously published trial by Dekkers $e t a l$, it was shown that 6-week treatment with dapagliflozin led to a significant decrease in urinary kidney injury molecule-1 (KIM-1) excretion, a marker of tubular injury, which strongly correlated with the change in albuminuria. ${ }^{3}$ Recently, in a post-hoc analysis of the VERTIS RENAL trial, it was shown that ertugliflozin was associated with a sustained lowering of the plasma levels of KIM-1 regardless of baseline kidney function. ${ }^{4}$ Such an effect has also been shown in other trials of smaller sample size. ${ }^{5}$ Thus, it seems that there are more benefits than expected with the use of SGLT-2 inhibitors in patients with LN. Based on the significant cardiovascular and renal burden of those patients, SGLT-2 inhibitors appear to be a promising treatment option, even in the absence of concomitant diabetes mellitus.

\section{Dimitrios Patoulias}

Second Propedeutic Department of Internal Medicine, Aristoteleio Panepistemio Thessalonikes, Thessaloniki, Greece

Correspondence to Dr Dimitrios Patoulias, Second Propedeutic Department of Internal Medicine, Aristoteleio Panepistemio Thessalonikes, 54642 Thessaloniki, Greece; dipatoulias@gmail.com
Contributors DP wrote the draft.

Funding The author has not declared a specific grant for this research from any funding agency in the public, commercial or not-for-profit sectors.

Competing interests None declared.

Patient and public involvement Patients and/or the public were not involved in the design, or conduct, or reporting, or dissemination plans of this research.

Patient consent for publication Not applicable.

Ethics approval This study does not involve human participants.

Provenance and peer review Commissioned; internally peer reviewed.

Data availability statement All data relevant to the study are included in the article. na.

(c) Author(s) (or their employer(s)) 2022. No commercial re-use. See rights and permissions. Published by BMJ.

\section{Check for updates}

To cite Patoulias D. Ann Rheum Dis Epub ahead of print: [please include Day Month Year]. doi:10.1136/annrheumdis-2021-221953

Received 8 December 2021

Accepted 9 December 202

Ann Rheum Dis 2022;0:1. doi:10.1136/annrheumdis-2021-221953

\section{ORCID iD}

Dimitrios Patoulias http://orcid.org/0000-0002-6899-684X

\section{REFERENCES}

1 Säemann M, Kronbichler A. Call for action in ANCA-associated vasculitis and lupus nephritis: promises and challenges of SGLT-2 inhibitors. Ann Rheum Dis 2021.annrheumdis-2021-221474.

2 Leatherwood C, Speyer CB, Feldman CH, et al. Clinical characteristics and renal prognosis associated with interstitial fibrosis and tubular atrophy (IFTA) and vascular injury in lupus nephritis biopsies. Semin Arthritis Rheum 2019;49:396-404.

3 Dekkers CCJ, Petrykiv S, Laverman GD, et al. Effects of the SGLT-2 inhibitor dapagliflozin on glomerular and tubular injury markers. Diabetes Obes Metab 2018;20:1988-93.

4 Liu H, Sridhar VS, Lovblom LE, et al. Markers of kidney injury, inflammation, and fibrosis associated with ertugliflozin in patients with CKD and diabetes. Kidney Int Rep 2021:6:2095-104.

5 Satirapoj B, Korkiatpitak P, Supasyndh O. Effect of sodium-glucose cotransporter 2 inhibitor on proximal tubular function and injury in patients with type 2 diabetes: a randomized controlled trial. Clin Kidney J 2019;12:326-32. 